Article

\title{
Road Safety Analysis of Urban Roads: Case Study of an Italian Municipality
}

\author{
Francesca Demasi, Giuseppe Loprencipe $(\mathbb{D}$ and Laura Moretti * \\ Department of Civil, Construction and Environmental Engineering, Sapienza University of Rome, 00184 Rome, \\ Italy; demasi.1462023@studenti.uniroma1.it (F.D.); giuseppe.loprencipe@uniroma1.it (G.L.) \\ * Correspondence: laura.moretti@uniroma1.it; Tel.: +39-06-4458-5114
}

Received: 4 October 2018; Accepted: 14 November 2018; Published: 1 December 2018

\begin{abstract}
Attention to the most vulnerable road users has grown rapidly over recent decades. The experience gained reveals an important number of fatalities due to accidents in urban branch roads. In this study, an analytical methodology for the calculation of urban branch road safety is proposed. The proposal relies on data collected during road safety inspections; therefore, it can be implemented even when historical data about traffic volume or accidents are not available. It permits us to identify geometric, physical, functional, and transport-related defects, and elements which are causal factors of road accidents, in order to assess the risk of death or serious injuries for users. Traffic volume, average speed, and expected consequences on vulnerable road users in case of an accident allow us to calculate both the level of danger of each homogeneous section which composes the road, and the hazard index of the overall branch. A case study is presented to implement the proposed methodology. The strategy proposed by the authors could have a significant impact on the risk management of urban roads, and could be used in decision-making processes to design safer roads and improve the safety of existing roads.
\end{abstract}

Keywords: road safety; road defects; urban branch road; index risk; road safety inspection

\section{Introduction}

User safety is one of the most important issues in road design. The Organization for Economic Co-operation and Development (OECD) demonstrated that in the last two decades, the trend of road accidents is not positive all over the world [1]. The problem is serious, as confirmed by the attention given to it at international level [2]. The United Nations General Assembly declared the years 2011-2020 as a Decade of Action for Road Safety [3]. At the European level, the trend of road fatalities since 2001 appears not to be compliant with the Road Safety Program pursued by the European Commission, which aims at halving road casualties by 2020 [4].

A non-negligible rate of road accidents (73\% in Italy according to [5]) occurs in urban areas, where externalities of motorized traffic (e.g., congestion, noise, and pollution) encourage the use of "soft mobility" [6,7]. In such conditions, different users and different vehicles share urban road spaces [8,9]. In the literature, several studies demonstrated that pedestrians, cyclists, and motorcyclists are the most vulnerable users in urban areas [10-12].

In order to prevent accidents and reduce their consequences on people, the system composed of drivers, vehicles, the environment, and roads should be investigated [8]. According to several studies available in the literature, most accidents are caused by bad behavior of drivers, i.e., the only ones capable of adapting their behavior towards non-living components [13,14]. However, it has been observed that the incorrect design or management of road infrastructure can induce bad behavior or failure to appreciate risk [15-18]. Therefore, in order to maximize on-going safety efforts, it is necessary to analyze each component of the road system and evaluate its effect on road safety. 
To this end, the European Directive 2008/96/EC [19] on the safety management of road infrastructure establishes management procedures ensuring the safety of road networks. It defines four basic tools for road safety management: Road Safety Impact Assessment, Road Safety Audit, Safety Ranking and Management of the Road Network in Operation, and Road Safety Inspections. These activities work on planning, design, and management of both constructed and to-be-constructed roads included in the Trans-European Transport Network (TEN-T). Some Member States transposed the Directive as a code of good practice also for their national roads which are not included in TEN-T. For example, in Italy, the transposition acts $[20,21]$ advised authorities to implement a road infrastructure safety management network composed of four phases: analysis, inspection, classification, and intervention. Particularly, Road Safety Inspections (RSI) should be carried out on existing roads in order to detect infrastructure elements/defects which could increase the rates of traffic conflicts and exacerbate their negative consequences.

Moreover, interesting and effective actions have been developed to promote tools and procedures in EU member states and in other countries [22-25].

The European Road Assessment Program (EuroRAP) has been developed by European road authorities to assess the risk to car occupants and highlight sections with the highest risk of death and serious injury [26]. It is based on objective variables: crash types and seriousness, distance and type of roadside obstacles, speed, and traffic level of the road.

In the USA, the AASHTO Highway Safety Manual (HSM) provides standardized and accurate methods for the estimation of both crash frequency or severity for urban roads and the effects of road safety measures $[27,28]$.

The New Zealand Transport Agency developed the procedure Road Infrastructure Safety Assessment to monitor road safety performances. Cross section, alignment, surface conditions, access ways, and statistical data on crashes are the examined variables [29]. Moreover, in New Zealand, procedures for Safety Audit of Existing Roads (SAER) allowed for the development of an empirical measure of safety according to a subjective scale depending on the relative hazard frequency and the crash severity probability [30].

In recent years, much research has analyzed the results from statistical data and RSI to evaluate safety condition towards physical components of road-system [31-33]. The proposed methods permits us to assess, at section and branch level, the current level of safety for the most vulnerable users, to identify the most critical conditions, and to implement correct strategic decisions [34]. The authors propose an original analytical model which is useful to assess the risk of road accidents in existing urban roads. The model relies on data collected during RSIs (e.g., geometric characteristics, road signs, and urban furniture, users' categories); therefore, it can be implemented even when historical data about traffic volume or accidents are not available. The value of applying this technique in the risk assessment of a specific urban branch road lies in the possibility of identifying the critical defects related to potential accidents which cause deaths or serious injury. This, in turn, provides the information required by the road management body to adopt a strategy in order to adopt mitigation strategies and protect citizens' well-being. The proposed method allows for an objective assessment of the risk level, and the numerical results of the analysis are comparable to a target level of risk to be defined during the analysis. Moreover, the method permits authorities to define guidelines for road design with the aim of creating safer roads for all types of users.

\section{Methods}

In this study, the authors proposed an innovative quantitative approach to assess the Branch Index Risk (BIR) and the Section Index Risk (SIR) of existing urban roads considering their geometry, layout, users, and traffic. BIR assesses the overall risk of road accidents in urban branch roads: the higher $B I R$ value, the lower the safety along the examined infrastructure stretch. Therefore, the value of $B I R$ depends on the Section Factor Risk $\left(S F R_{j, r}\right.$ ) of each homogeneous section $j$ which composes the branch $r$. Each homogeneous section is $100 \mathrm{~m} \pm 20 \%$-long: road branches are considered homogeneous if they 
have uniform/homogeneous attributes related to physical and operating conditions (i.e., accident rate, geometric layout, composition of cross section, traffic spectrum, average operating speed) [35]. This approach allows for the comparison of "density" of hazardous elements/defects between different (short) sections whose length is suited to the considered urban context. Moreover, it gives good results in terms of fitting the safety performance of road sections, as confirmed by Cafiso et al. [36].

$S F R_{j, r}$ takes into account both the general characteristics of $r$ (i.e., type and frequency of hazardous elements/defects, expected damage on vulnerable road users, and traffic level), and all $n$ elements which affect the dangerousness of $j$. Equation (1), which complies with an approach recently proposed to analyze and plan maintenance of road safety barriers [32], allows us to calculate $S F R_{j, r}$ :

$$
S F R_{j, r}=\Sigma^{\mathrm{n}_{\mathrm{i}=1}} B_{i} \times K_{1 i} \times K_{2 i} \times K_{3} \times K_{4 i} \times K_{5 i}
$$

$B_{i}$ is the base value associated to defects $i$ which are along $j$.

$K_{1 i}$ is the priority factor of the category to which the element $i$ belongs.

$K_{2 i}$ is the vulnerability factor of users (i.e., pedestrians, cyclists and motorcyclists) along $r$; and it depends on their volume.

$K_{3}$ is the motorized traffic factor of $r$.

$K_{4 i}$ is the hazardousness factor; it depends on the consequences of defect $i$ on the most vulnerable road users.

$K_{5 i}$ is the extension factor; it depends on continuous or discrete elements/defects $i$ along $j$.

Given $S F R_{j, r}$, the corresponding value of $S I R$ can be calculated according to Equation (2)

$$
S I R_{j, r}=S F R_{j, r} / S F R_{\max , r} \times 100
$$

where $S I R_{j, r}$ is the Section Index Risk of the section $j$ belonging to $r$, and $S F R_{\max , r}$ is the highest value of $S F R_{r}$ by attributing the maximum values to defects found on $r$.

Therefore, $S F R_{j, r}$ depends on the detected road elements/defects and the road users of the section $j$, and $S I R_{j, r}$ depends on the comparison between the attributed and the maximum values of $K_{1 i}, K_{2 i}$, $K_{3}, K_{4 i}$, and $K_{5 i}$.

Similarly, the Branch Index Risk $B I R_{r}$ can be calculated according to Equation (3):

$$
B I R_{r}=R_{r} / R_{\max , r} \times 100
$$

where $R_{r}$ is the sum of the $S I R_{j, r}$ of $\mathrm{m}$ sections which compose the road branch $r$ given by Equation (4)

$$
R_{r}=\Sigma \mathrm{m}_{\mathrm{j}=1} S I R_{j, r}
$$

where $R_{\max , r}$ is the reference value of the Risk Factor given by Equation (5)

$$
R_{\max , r}=m \times S F R_{\max , r}
$$

Similar to $S I R_{j, r}, B I R_{r}$ depends on the attributed values of $K_{1 i}, K_{2 i}, K_{3}, K_{4 i}$, and $K_{5 i}$, and on the defects found along $r$. Both $S I R_{j, r}$ and $B I R_{r}$ range between 0 and 1 .

The implementation of the proposed method requires road inspections to identify and categorize elements and/or defects of infrastructure which could cause accidents. The authors identified 9 categories of elements/defects: geometry $(\mathrm{G})$, cross-section $(\mathrm{C})$; private access $(\mathrm{A})$; pavement $(\mathrm{P})$; lighting (L); road signs (S); intersection (J); urban furniture (F); and stopping (ST). The attribution of possible values of $K_{1 i}, K_{2 i}, K_{4 i}$, and $K_{5 i}$, and $B_{i}$ required interviewing technicians from different backgrounds, as well as academic experts in the fields of roads (both geometry and safety), urban planning, transport management, and human health. Eight road engineers, eight urbanists, seven traffic managers, and six traumatologists were interviewed. The authors defined, for each variable, 
the maximum and minimum value, then each technician attributed the values within the established ranges. Finally, the geometric mean has been used to aggregate individual judgements.

Table 1 lists the priority factors $K_{1}$ for each category.

Table 1. Priority factor values of considered elements/defects.

\begin{tabular}{ccc}
\hline Category & Code & $\boldsymbol{K}_{\mathbf{1}}$ \\
\hline Geometry & $\mathrm{G}$ & 0.9 \\
Cross-section & $\mathrm{C}$ & 1.0 \\
Private access & $\mathrm{A}$ & 0.9 \\
Pavement & $\mathrm{P}$ & 0.8 \\
Lighting & $\mathrm{L}$ & 0.5 \\
Road signs & $\mathrm{S}$ & 0.7 \\
Intersection & $\mathrm{J}$ & 1.0 \\
Urban furniture & $\mathrm{F}$ & 0.6 \\
Stopping & $\mathrm{ST}$ & 0.4 \\
\hline
\end{tabular}

Taken together, the authors identified 55 road elements/defects which can cause accidents. Their base values $B_{i}$ satisfy Equation (6) and are listed in Table 2. Road layout and geometry were evaluated against the Italian standards and recommendations about the geometric and functional characteristics of roads [37] and intersections [38], road infrastructure safety management [21], and road lighting [39]. These standards were considered as references to identify "not compliant" conditions, and to assign the $B_{i}$ values.

$$
1 \leq B_{i} \leq 4
$$

$K_{2 i}$ depends on the observed traffic condition of vulnerable users (i.e., pedestrians, cyclists, and motorcyclists) which are exposed to the risk induced by defect $i$. The Highway Capacity Manual [40] suggests performing surveys during a 15 min count period in order to obtain the traffic volume data. The authors observed the traffic flow when weather conditions were not an obstacle to traffic, and when all work- and school-related activities were ongoing. Finally, they calculated $K_{2 i}$ according to Equation (7).

$$
K_{2 i}=K_{P i} \times K_{C i} \times K_{M i}
$$

where $K_{P i}, K_{C i}$, and $K_{M i}$ depend on the pedestrian, cyclist, and motorcyclist flow, respectively. Their values satisfy Equations (8)-(10), and depend on the traffic volume observed along the overall examined branches, if the analysis involves a road network.

$$
\begin{aligned}
& 1 \leq K_{P i} \leq 2.5 \\
& 1 \leq K_{C i} \leq 2.5 \\
& 1 \leq K_{M i} \leq 2.5
\end{aligned}
$$

Particularly, having considered all the examined branches, the average hourly flow of cyclists and motorcyclists ( $A C F$ and $A M F$, respectively), and their standard deviation (DCF and $D M F$, respectively) are calculated. Finally, these values are compared to the hourly flow of cyclists and motorcyclists $\left(A C F_{r}\right.$ and $A M F_{r}$, respectively) and the standard deviations $\left(D C F_{r}\right.$ and $D M F_{r}$, respectively) of the examined branch $r$ in order to calculate $K_{C i}$ and $K_{M i}$, respectively (Table 3). 
Table 2. Base values of elements/defects.

\begin{tabular}{|c|c|c|}
\hline Description & Code & $B_{i}$ \\
\hline Geometry: low planimetric radius; not enough stopping sight distance & G1 & 3 \\
\hline Geometry: steep longitudinal slope & G2 & 3 \\
\hline Carriageway: narrow lane width & $\mathrm{C} 1$ & 1 \\
\hline Carriageway: missing shoulder & $\mathrm{C} 2$ & 2 \\
\hline Carriageway: narrow shoulder width & $\mathrm{C} 3$ & 1 \\
\hline Carriageway: median not appropriate & $\mathrm{C} 4$ & 2 \\
\hline Carriageway: missing sidewalk & C5 & 4 \\
\hline Carriageway: narrow sidewalk (less than 0.5 m-wide) & C6 & 2 \\
\hline Carriageway: irregular sidewalk pavement & $\mathrm{C} 7$ & 1 \\
\hline Carriageway: distressed sidewalk pavement induces pedestrians to use the carriageway & $\mathrm{C} 8$ & 4 \\
\hline Carriageway: missing waiting area at bus stops & C9 & 4 \\
\hline Carriageway: narrow waiting area at bus stops & $\mathrm{C} 10$ & 2 \\
\hline Carriageway: missing pedestrian connections to and from the bus stop & $\mathrm{C} 11$ & 3 \\
\hline Carriageway: missing accessible connections to and from the bus stop & $\mathrm{C} 12$ & 2 \\
\hline Carriageway: pedestrian crossing without ramps & $\mathrm{C} 13$ & 2 \\
\hline Carriageway: ramps not aligned to pedestrian crossing & $\mathrm{C} 14$ & 2 \\
\hline Carriageway: missing pedestrian crossing & $\mathrm{C} 15$ & 4 \\
\hline Carriageway: more than $12 \mathrm{~m}$-long crossing & C16 & 4 \\
\hline Carriageway: distressed pavement at pedestrian crossing & $\mathrm{C} 17$ & 2 \\
\hline Carriageway: lack of visibility (both at pedestrian crossing or not) & $\mathrm{C} 18$ & 4 \\
\hline Carriageway: missing tactile paths & C19 & 2 \\
\hline Carriageway: not appropriate tactile paths & $\mathrm{C} 20$ & 1 \\
\hline Carriageway: missing cycle path & $\mathrm{C} 21$ & 3 \\
\hline Carriageway: narrow cycle path & $\mathrm{C} 22$ & 2 \\
\hline Private access: not compliant position & A1 & 2 \\
\hline Private access: lack of visibility & A2 & 3 \\
\hline Private access: lack of ramps & A3 & 1 \\
\hline Pavement: irregular pavement & P1 & 3 \\
\hline Pavement: joint faulting and drainage distress & P2 & 2 \\
\hline Pavement: tram crossing & P3 & 2 \\
\hline Pavement: inefficient drainage system & $\mathrm{P} 4$ & 3 \\
\hline Pavement: missing drainage system & P5 & 2 \\
\hline Lighting: missing lighting system & L1 & 4 \\
\hline Lighting: inefficient drainage system & L2 & 2 \\
\hline Road signs: missing horizontal road markings & S1 & 4 \\
\hline Road signs: not complete horizontal road markings & S2 & 3 \\
\hline Road signs: not compliant horizontal road markings & S3 & 3 \\
\hline Road signs: missing roadside signs & S4 & 4 \\
\hline Road signs: not visible roadside signs & S5 & 3 \\
\hline Road signs: not complete roadside signs & S6 & 2 \\
\hline Road signs: not compliant roadside signs & S7 & 3 \\
\hline Road signs: missing traffic light & S8 & 4 \\
\hline Road signs: wrong phases of traffic light & S9 & 3 \\
\hline Road signs: wrong installation of traffic light & S10 & 2 \\
\hline Road signs: not visible traffic light & S11 & 2 \\
\hline Intersection: lack of visibility & $\mathrm{J} 1$ & 4 \\
\hline Intersection: missing reserved lane & $\mathrm{J} 2$ & 3 \\
\hline Intersection: hazardous maneuvers & $\mathrm{J} 3$ & 3 \\
\hline Intersection: missing weaving section & $\mathrm{J} 4$ & 3 \\
\hline Urban furniture: not compliant safety barriers & F1 & 3 \\
\hline Urban furniture: missing safety barriers & F2 & 4 \\
\hline Urban furniture: urban furniture forces pedestrians to use carriageway & F3 & 2 \\
\hline Urban furniture: lack of visibility at intersection due to urban furniture & F4 & 4 \\
\hline Urban furniture: urban furniture occupies shoulder and/or lane & F5 & 3 \\
\hline Urban furniture: missing maintaining greenery at roadside & F6 & 1 \\
\hline Stopping: illegal parking & ST1 & 1 \\
\hline
\end{tabular}


Table 3. Values of the vulnerability factor $K_{2 i}$.

\begin{tabular}{|c|c|c|c|c|}
\hline Users & Observed Condition & Traffic Flow Condition & Code & $K_{2}$ Values \\
\hline \multirow{4}{*}{ Pedestrians } & Pedestrians not exposed to defect $i$ & - & \multirow{4}{*}{$K_{P i}$} & 1.0 \\
\hline & $\begin{array}{l}\text { Not more than } 5 \text { commercial activities and/or any } \\
\text { bus stops are in the examined section. }\end{array}$ & Low & & 1.5 \\
\hline & $\begin{array}{l}\text { Not more than } 10 \text { commercial activities and/or not } \\
\text { more than } 2 \text { bus stops are in the examined section }\end{array}$ & Medium & & 2.0 \\
\hline & $\begin{array}{l}\text { The examined section is very attractive: more than } \\
10 \text { commercial activities and } 2 \text { bus stops, schools, } \\
\text { public offices, or collective spaces are. }\end{array}$ & High & & 2.5 \\
\hline \multirow{4}{*}{ Cyclists } & $\begin{array}{l}\text { Cyclists are not exposed to defect } i \text {. Cyclists do not } \\
\text { use or are not admitted }\end{array}$ & - & \multirow{4}{*}{$K_{C i}$} & 1.0 \\
\hline & $A C F_{r}<A C F-D C F$ & Low & & 1.5 \\
\hline & $A C F-D C F \leq A C F_{r}<A C F+D C F$ & Medium & & 2.0 \\
\hline & $A C F_{r}>A C F+D C F$ & High & & 2.5 \\
\hline \multirow{4}{*}{ Motorcyclists } & $\begin{array}{l}\text { Motorcyclists are not exposed to defect } i \text {. } \\
\text { Motorcyclists do not use or are not admitted }\end{array}$ & - & \multirow{4}{*}{$K_{M i}$} & 1.0 \\
\hline & $A M F_{r}<A M F-D M F$ & Low & & 1.5 \\
\hline & $A M F-D M F \leq A M F_{r}<A M F+D M F$ & Medium & & 2.0 \\
\hline & $A M F_{r}>A M F+D M F$ & High & & 2.5 \\
\hline
\end{tabular}

The motorized traffic factor $K_{3}$ depends on the observed volume of motorized vehicles along the surveyed stretch. According to [41-44], the authors assumed that the higher their average speed, the greater the danger of exposure for vulnerable users. Therefore, the values of $K_{3}$ in Table 4 depend on the typical observed traffic fluidity and the number of daylight hours with congested traffic flow. The term "congested flow" complies with the methodology proposed by [45] to evaluate the level of service of an urban arterial: this condition occurs when the percentage speed reduction from free flow speed appears greater than $50 \%$.

Table 4. Values of the motorized traffic factor $K_{3}$.

\begin{tabular}{cccc}
\hline \multirow{2}{*}{ Typical Traffic Flow } & \multicolumn{3}{c}{ Daylight Hours with Congested Traffic Flow (h) } \\
\cline { 2 - 4 } & $\mathbf{> 5}$ & $\mathbf{3 - 5}$ & $<3$ \\
\cline { 2 - 4 } & & $\boldsymbol{K}_{\mathbf{3}}$ \\
\hline Stable flow & 2.0 & 2.5 & 2.5 \\
Approaching unstable flow & 1.5 & 2.0 & 2.5 \\
Unstable flow/Stop\&go & 1.5 & 1.5 & 2 \\
\hline
\end{tabular}

The hazardousness factor $K_{4 i}$ depends on the expected fatality induced by the defect $i$ on vulnerable road users. It is calculated according to Equation (11)

$$
K_{4 i}=K_{4 V i} \times K_{4 P i}
$$

where $K_{4 V i}$ and $K_{4 P i}$ refer to expected consequences on motorized vehicle users (both drivers and passengers), and non-motorized users (pedestrians and cyclists), respectively. Their values satisfy Equations (12) and (13), and are listed in Table 5.

$$
\begin{aligned}
& 1 \leq K_{4 V i} \leq 2.5 \\
& 1 \leq K_{4 P i} \leq 5.0
\end{aligned}
$$


Table 5. Values of the hazardousness factor $K_{4 i}$.

\begin{tabular}{|c|c|c|c|c|}
\hline Road users & Condition & Hazardousness & Code & $K_{4}$ Values \\
\hline \multirow{4}{*}{$\begin{array}{c}\text { Motorized vehicle } \\
\text { users }\end{array}$} & Motorized vehicle users are not exposed to defect $i$ & - & \multirow{4}{*}{$K_{4 V i}$} & 1.0 \\
\hline & $\begin{array}{l}\text { Motorized vehicle users are not damaged by defect } i \text {, } \\
\text { or crashes occur at not more than } 40 \mathrm{~km} / \mathrm{h}\end{array}$ & Low & & 1.5 \\
\hline & Crashes occur at $40-60 \mathrm{~km} / \mathrm{h}$ & Medium & & 2.0 \\
\hline & Crashes occur at more than $60 \mathrm{~km} / \mathrm{h}$ & High & & 2.5 \\
\hline \multirow{5}{*}{$\begin{array}{c}\text { Non-motorized } \\
\text { users }\end{array}$} & Non-motorized vulnerable users not exposed to defect $i$ & - & \multirow{5}{*}{$K_{4 P i}$} & 1.0 \\
\hline & $\begin{array}{l}\text { Non-motorized vulnerable users are not damaged by } \\
\text { defect } i \text {, or crashes with motorized vehicles occur at not } \\
\text { more than } 30 \mathrm{~km} / \mathrm{h}\end{array}$ & Low & & 2.0 \\
\hline & Cashes occur at $30-40 \mathrm{~km} / \mathrm{h}$ & Medium & & 3.0 \\
\hline & Cashes occur at $40-50 \mathrm{~km} / \mathrm{h}$ & High & & 4.0 \\
\hline & Cashes occur at more than $50 \mathrm{~km} / \mathrm{h}$ & Critical & & 5.0 \\
\hline
\end{tabular}

The established ranges for $K_{4 V i}$ and $K_{4 P i}$ take into account that at the same speed, consequences on vulnerable users are higher than on users of motorized vehicles. On the road, vulnerable users conflict with vehicles with larger dimensions and masses; cyclists and pedestrians clearly constitute the "unprotected" element, and they are more exposed in the event of an accident, as confirmed by [46]. Indeed, Wramborg defined probability curves to represent the fatality risk versus collision speed when a motorized vehicle collides with a vulnerable user, or frontal or hard object collision occurs to motorized vehicles.

$K_{5 i}$ is the extension factor of each element $i$ found along $j$. According to Table 6, it considers both surveyed continuous and discrete elements/defects.

Table 6. Values of the extension factor $K_{5 i}$.

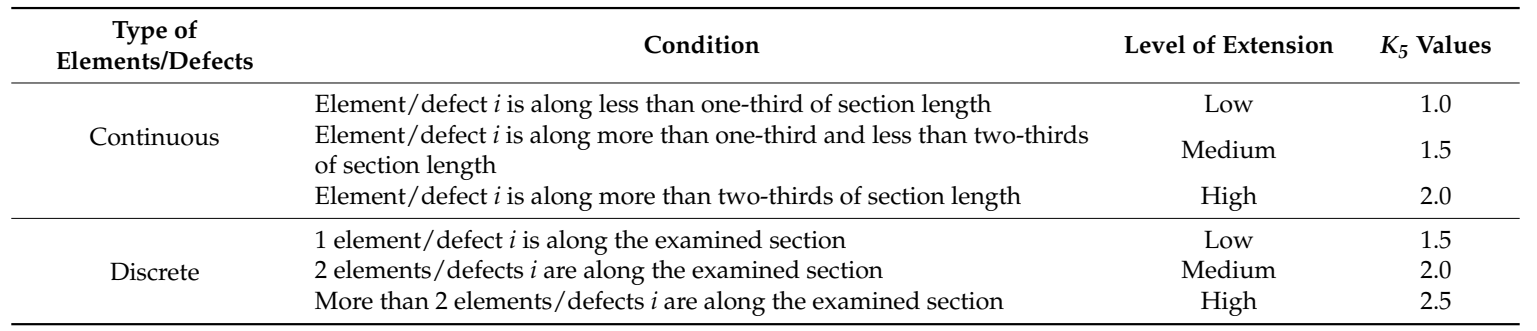

Given the above procedures, it is possible to simulate values of $B I R_{S}$ and define appropriate classes of risk. To this end, the authors considered six probabilistic classes of risk level, as usually done for transport infrastructure risk assessment [47-53]. The definition of ranges for each class requires a significant number of monitored branches. Monte Carlo simulations were used to generate a distribution of simulated $B I R_{S}$ obtained from randomly-assigned values of the proposed variables. Therefore, the Monte Carlo technique gave a virtual sample useful to study the statistical variability of $B I R$, assuming that the virtual sample was comparable to the real (surveyed) one. According to the Central Limit Theorem [54], as the number of samples from any population increases, the probability distribution of the means will approach a normal distribution. Therefore, it was possible to compare the distribution of simulated $B I R_{S}$ to a Gaussian distribution. Figure 1 shows the results from 3000 simulations, and it compares the simulated and analytical frequency curves: the former derives from the Monte Carlo simulation, the latter represents the Gaussian curve [55].

Figure 2 compares the cumulative frequency curves of the simulated and analytical distributions: their trend confirms the appropriateness of the procedure. 


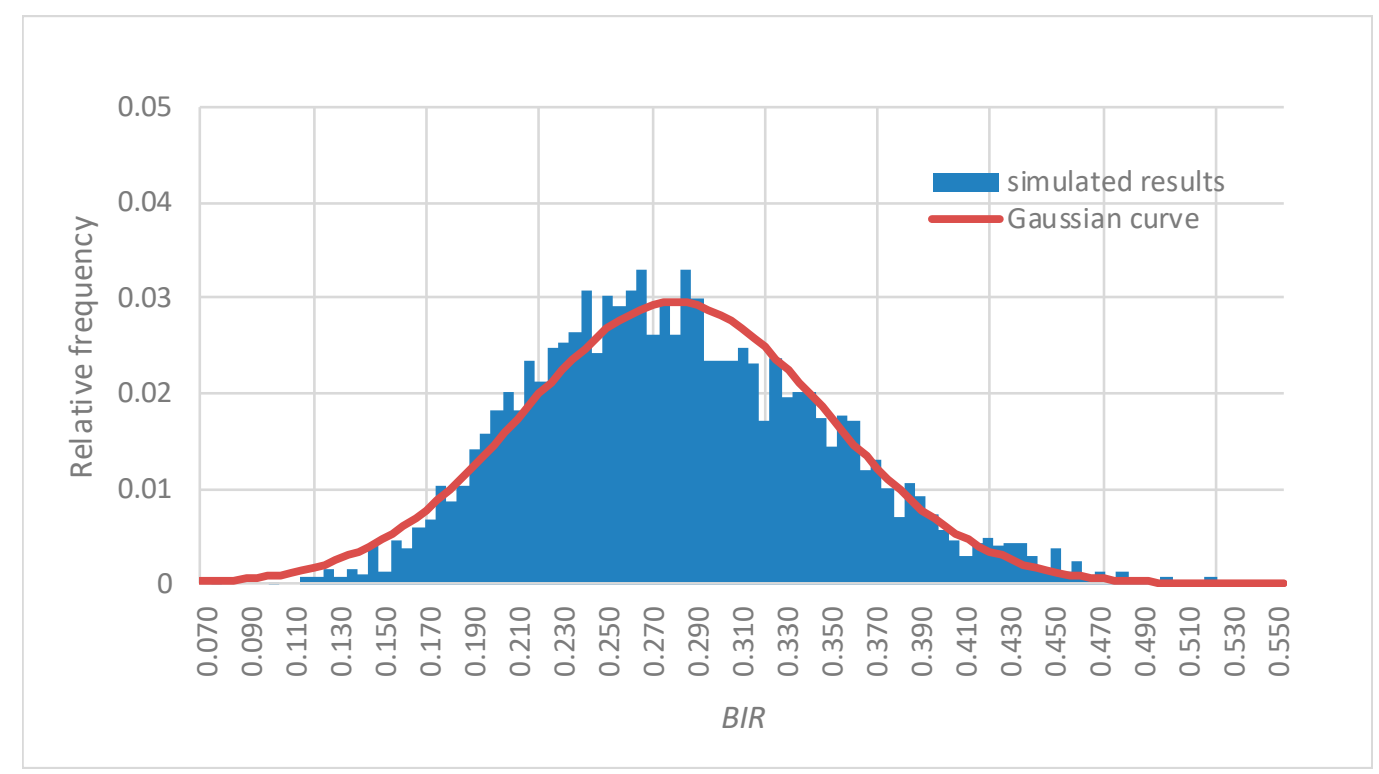

Figure 1. Comparison between simulated and analytical relative frequency curves.

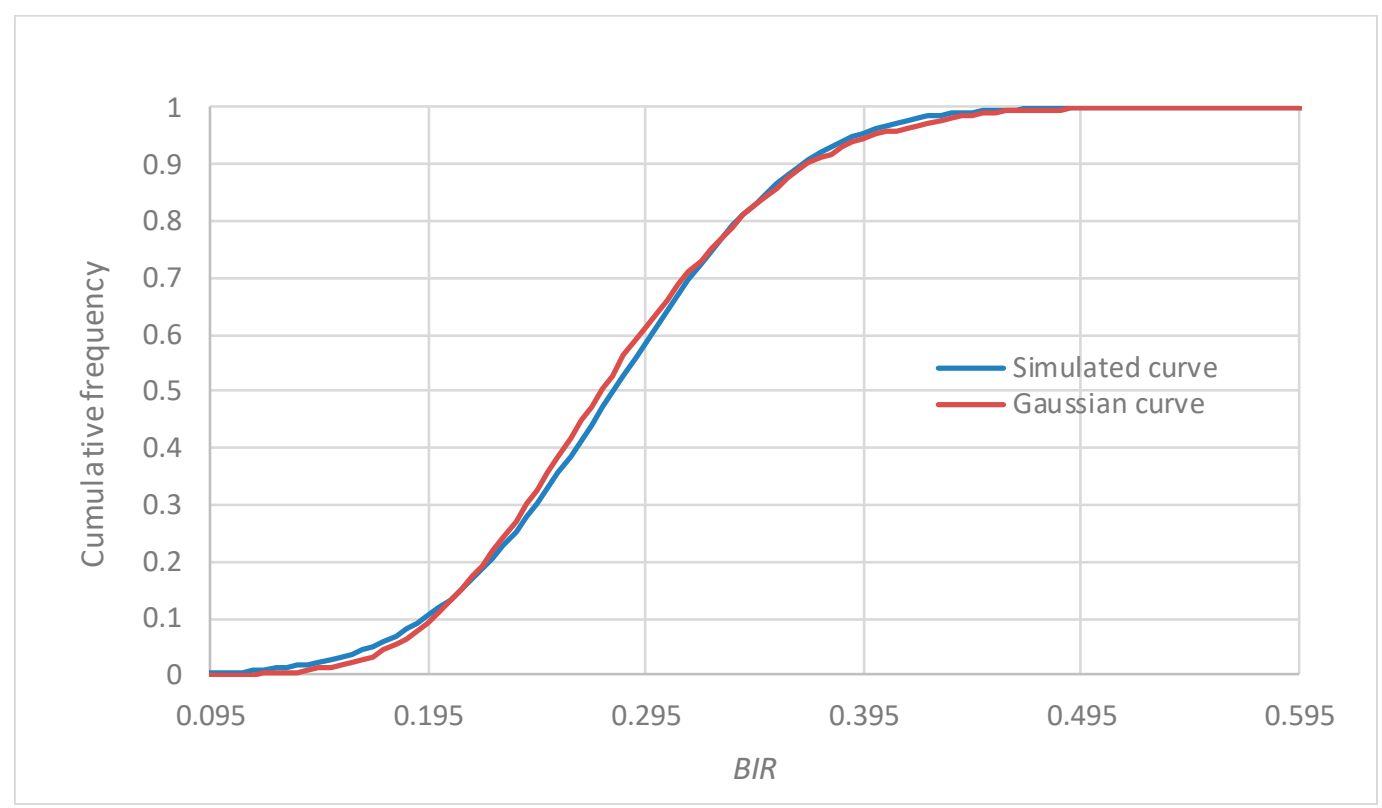

Figure 2. Comparison between simulated and analytical cumulative frequency curves.

Table 7 lists the six classes of $B I R$, their minimum and maximum values, and chromatic categorization.

Table 7. Classes of risk.

\begin{tabular}{cccccc}
\hline \multirow{2}{*}{ Class } & \multirow{2}{*}{ Risk Level } & Criterion & \multicolumn{2}{c}{ BIR (\%) } & \multirow{2}{*}{ Chromatic Categorization } \\
\cline { 4 - 4 } & & Minimum & Maximum & \\
\hline I & Not relevant & $\mathrm{I}<\mu-2 \sigma$ & 0 & 14.5 & White \\
II & Low & $\mu-2 \sigma<\mathrm{I}<\mu-\sigma$ & $>14.5$ & 21.2 & Green \\
III & Moderate & $\mu-\sigma<\mathrm{I}<\mu$ & $>21.2$ & 28.0 & Yellow \\
IV & High & $\mu<\mathrm{I}<\mu+2 \sigma$ & $>28.0$ & 34.8 & Orange \\
V & Very high & $\mu+2 \sigma<\mathrm{I}<\mu+2 \sigma$ & $>34.8$ & 41.5 & Red \\
VI & Critical & $\mathrm{I}>\mu+2 \sigma$ & $>41.5$ & 100 & Burgundy \\
\hline
\end{tabular}


The proposed method could be applied by policy and decision makers when they have to manage urban road safety because it provides results that could be used to critically approach this strategic sector whose impacts are economic, social, and environmental. Indeed, input data are available to a road management body, and the presented method is comprehensive and versatile; therefore, it may be applied to different urban scenarios varying the examined variables and their factors.

\section{Case Study}

The proposed methodology has been applied on multiple branches totaling $50 \mathrm{~km}$ together in an Italian municipality in order to assess their BIR values. All the roads had the same classification: two-lane urban roads with parking spaces and sidewalks on both sides (Figure 3). Their maximum allowable speed was $50 \mathrm{~km} / \mathrm{h}$.

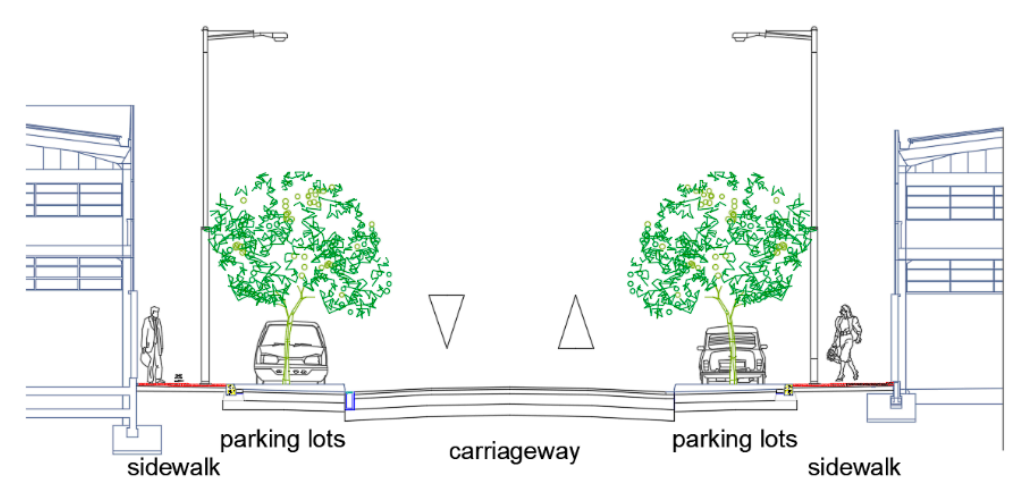

Figure 3. Cross-section of the examined urban roads.

For the sake of brevity, in this study, the authors present the most interesting and critical roads, where users have to perform crucial and dangerous maneuvers (e.g., intersections without traffic lights, poor visibility, many conflict points). Table 8 summarizes geometric and technical characteristics of the selected roads: they are 7 branches (i.e., ROAD1 to ROAD7) with similar geometric and traffic characteristics.

Table 8. Characteristics of the selected roads.

\begin{tabular}{cccccc}
\hline Branch & Total Length (m) & Number of Sections & Minimum SIR (\%) & Maximum SIR (\%) & $\begin{array}{c}\text { Most Frequently } \\
\text { Detected Base Values }\end{array}$ \\
\hline ROAD1 & 1700 & 17 & 32.3 & 59.8 & 2 \\
ROAD2 & 1400 & 14 & 8.1 & 61.7 & 3 \\
ROAD3 & 550 & 5 & 18.5 & 31.1 & 3 \\
ROAD4 & 2000 & 20 & 15.0 & 30.0 & 2 \\
ROAD5 & 650 & 6 & 4.8 & 30.6 & 3 \\
ROAD6 & 2450 & 25 & 0.1 & 31.21 & 3 \\
ROAD7 & 1400 & 14 & & & 3 \\
\hline
\end{tabular}

Figure 4a to $\mathrm{f}$ show some of the most frequently-detected defects: irregular pavement, narrow sidewalk, inefficient lighting system, urban furniture occupies shoulder and/or lane, pedestrian crossing without ramps, and not visible traffic light, respectively. 

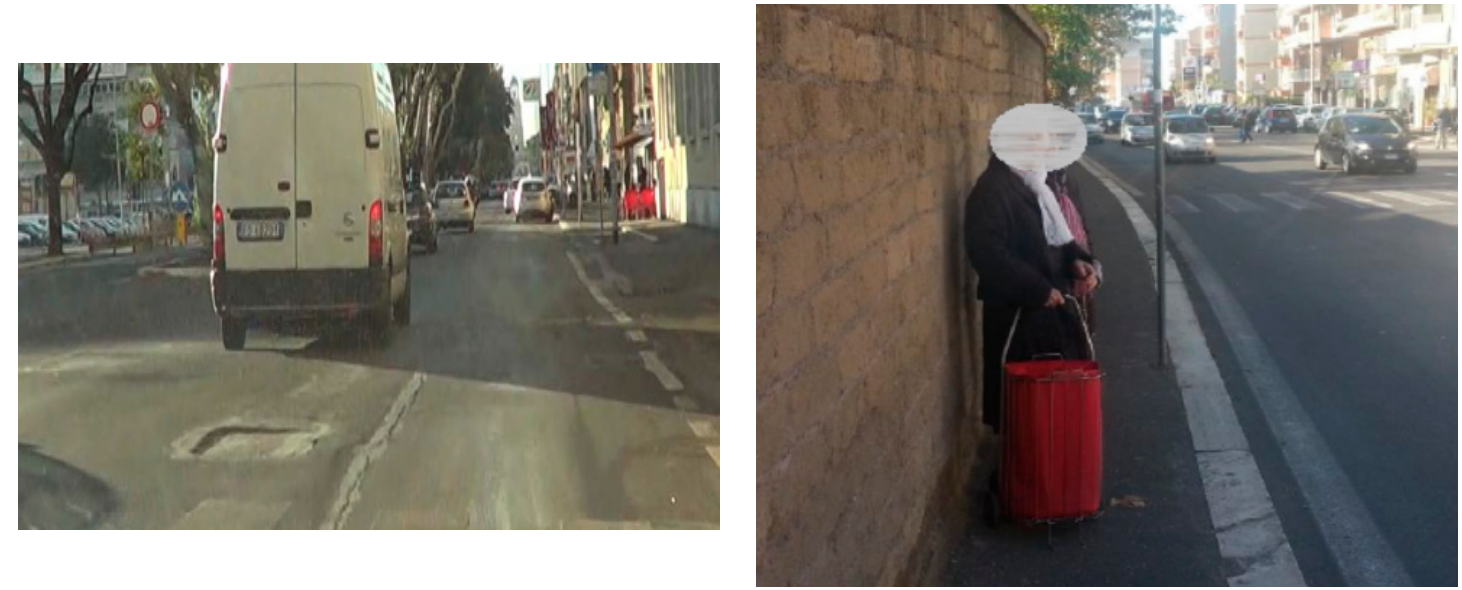

(a)

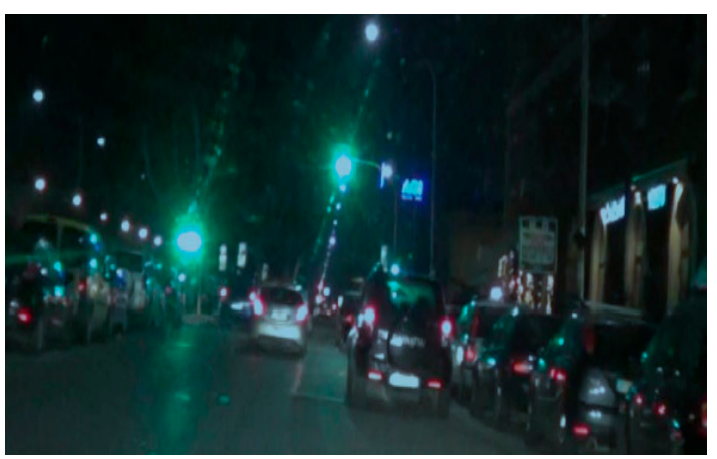

(b)

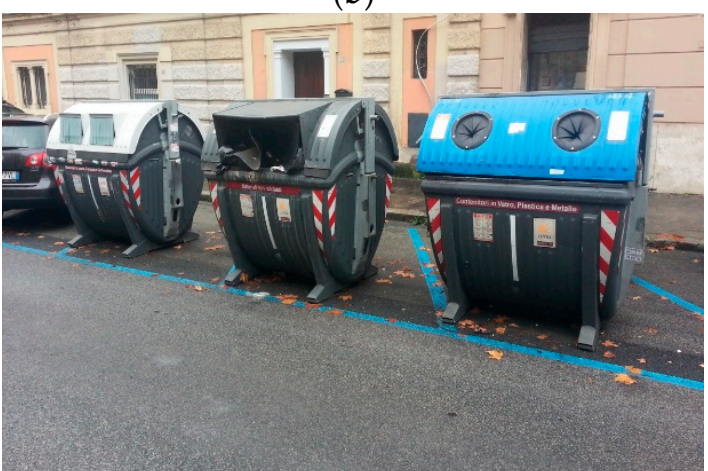

(c)

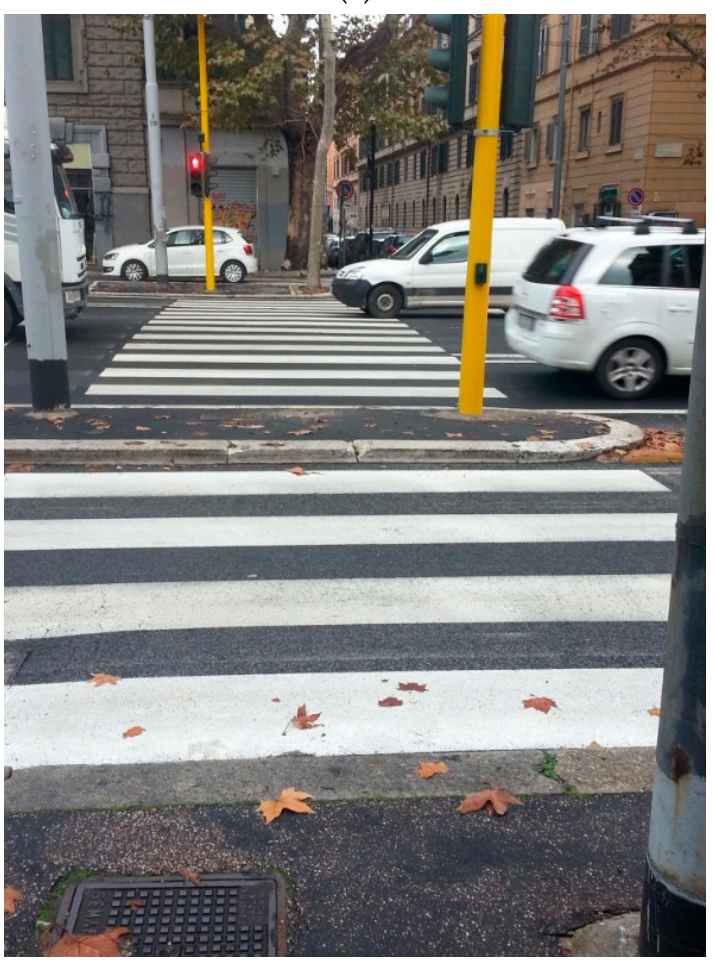

(e)

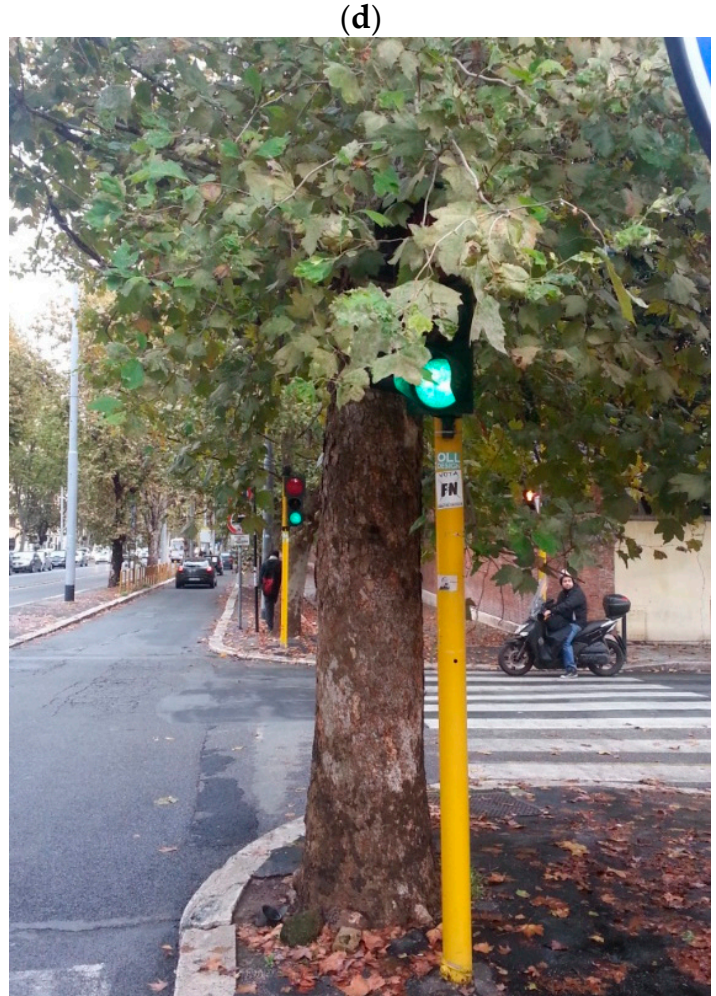

(f)

Figure 4. Most frequently detected distresses. (a) Irregular pavement P1 $\left(B_{i}=3\right)$; (b) Narrow sidewalk C6 $\left(B_{i}=2\right) ;(\mathbf{c})$ Inefficient lighting system L2 $\left(B_{i}=2\right)$; (d) Urban furniture occupies shoulder and/or lane F5 $\left(B_{i}=3\right)$; (e) Pedestrian crossing without ramps C13 $\left(B_{i}=2\right)$; (f) Not visible traffic light S11 $\left(B_{i}=2\right)$. 
The bar graph in Figure 5 represents, in descending order, $B I R_{S}$ (i.e., blue bars) to better compare them to the accident density $(A D)$ (i.e., orange bars) retrieved by the authors from the Italian statistical geo-referenced database of occurred accidents [56].

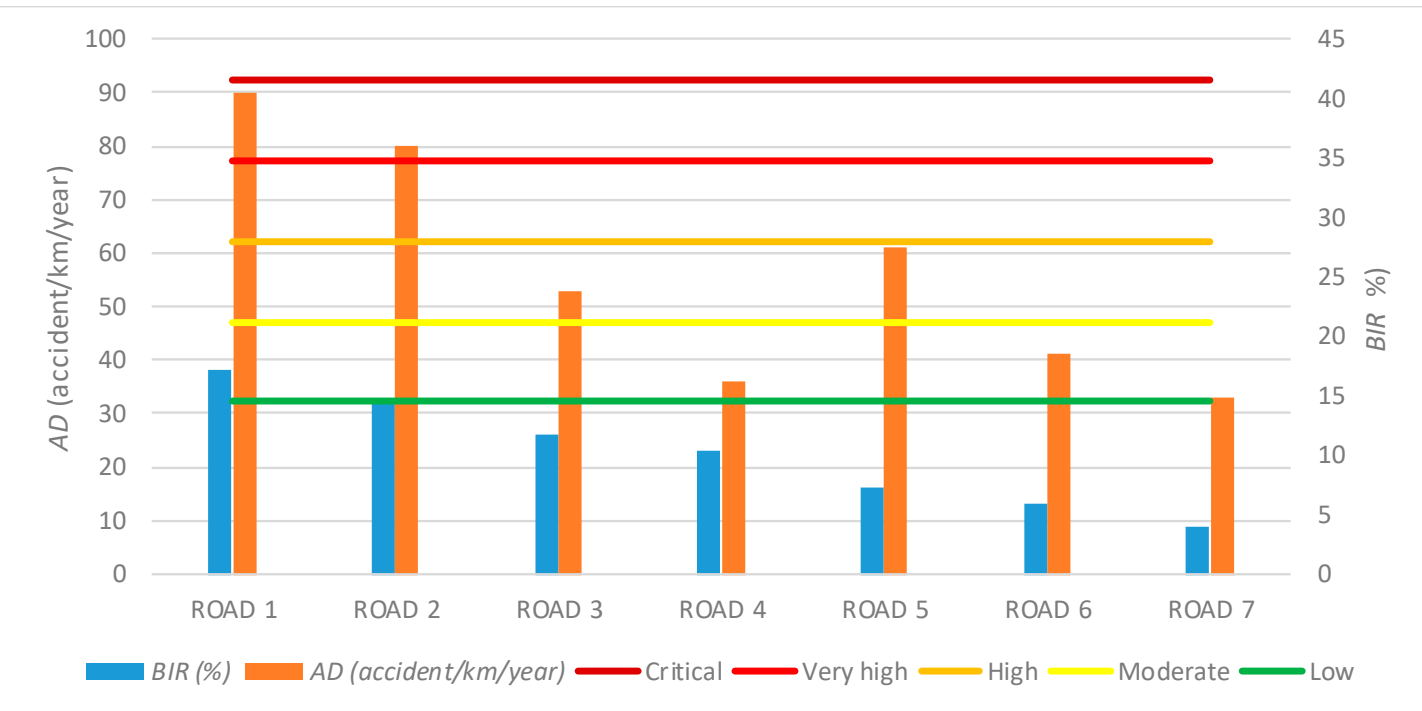

Figure 5. Comparison of $B I R$ values and accident density for different roads.

In Figure 5, a good correlation between the data from surveys and the statistical data about accidents appears: the higher the accident density $(A D)$, the greater the BIR values. ROAD1 and ROAD2 have the highest values of both $B I R$ and $A D$. ROAD5 does not comply with this point because $A D$ and $B I R$ values refer to different conditions. Indeed, $A D$ refers to 2015 , while surveys to obtain $B I R$ occurred in 2017, after safety works carried out in 2016. Therefore, ROAD5 has been removed from analysis of correlation between road defects and accidents in order to define Equation (14):

$$
A D=2 B I R+9.6
$$

Moreover, the analysis of $S I R_{j, r}$ allowed for the identification of the most hazardous sections according to Table 7. Figure 6 shows the results obtained for ROAD7. Its risk map is in Figure 7, where it is possible to identify sections 4 and 7 (i.e., orange and yellow bars, respectively).

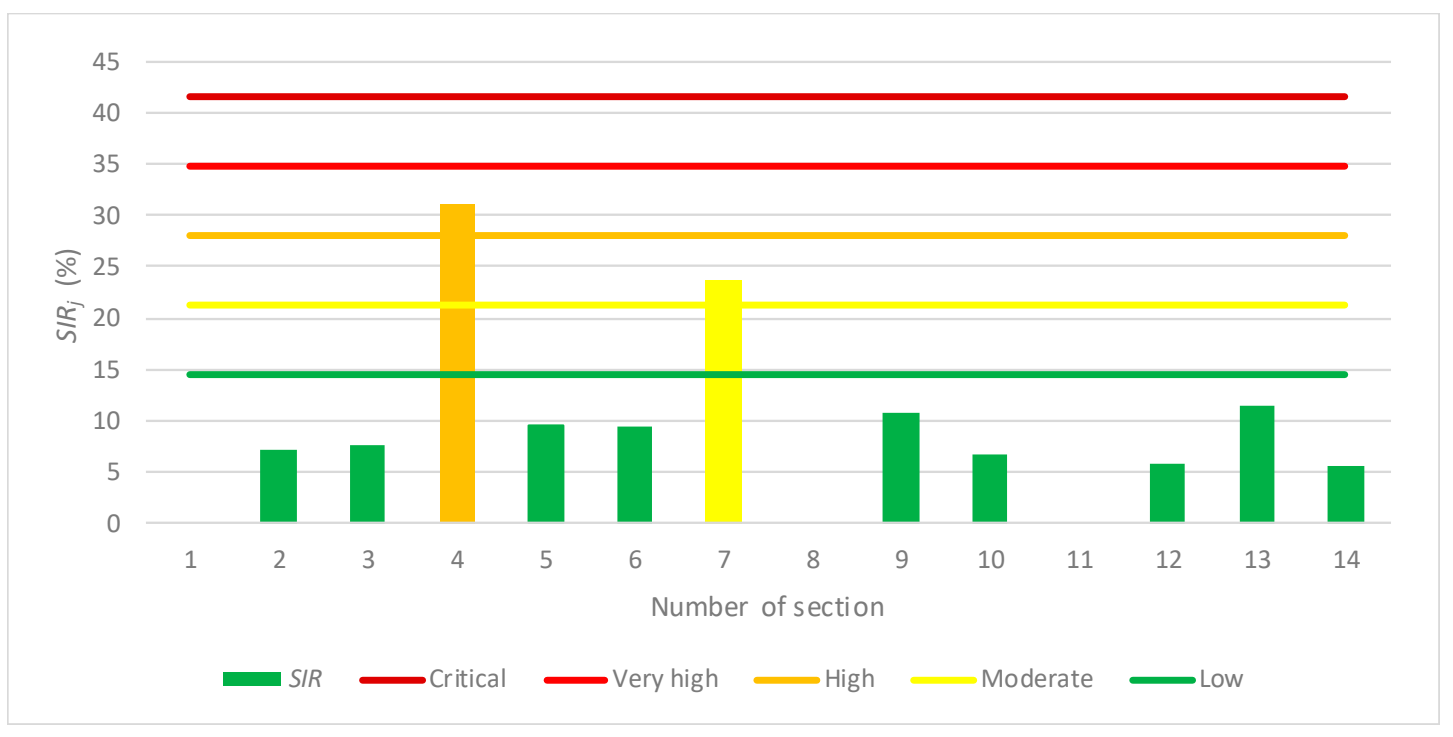

Figure 6. $S I R_{j}$ of ROAD7. 


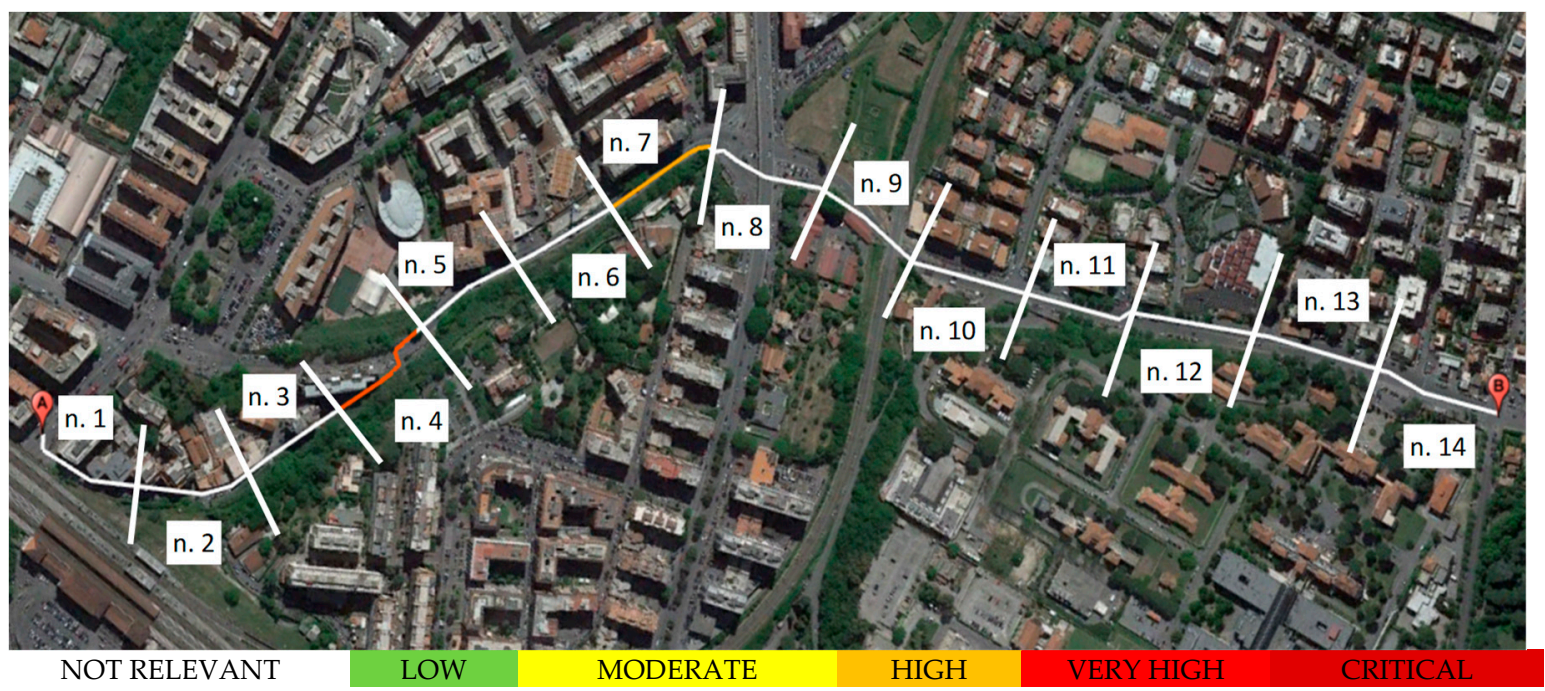

Figure 7. Map of risk of ROAD7.

BIR of ROAD7 is equal to $9.15 \%$ (i.e., not relevant level of risk); however, according to Figures 6 and 7 , it is possible to observe that section $\mathrm{n}$. 4 has a high level of risk (i.e., 31.2\%). Table 9 lists data used to perform the risk assessment.

Table 9. Input data for $B I R_{4, R O A D 7}$ calculation.

\begin{tabular}{ccccccccc}
\hline Defect & Code & $\boldsymbol{B}_{\boldsymbol{i}}$ & $\boldsymbol{K}_{\mathbf{1 i}}$ & $\boldsymbol{K}_{\mathbf{2 i}}=\boldsymbol{K}_{\boldsymbol{P}}$ & $\boldsymbol{K}_{\mathbf{3}}$ & $\boldsymbol{K}_{\mathbf{4 i}}$ & $\boldsymbol{K}_{5 \boldsymbol{i}}$ & SFR $_{\mathbf{4}, \boldsymbol{R O A D 7}}$ \\
\hline Missing sidewalk & $\mathrm{C} 5$ & 4 & 1 & 1.5 & 2.5 & 5.0 & 1.5 & 112.50 \\
Hazardous maneuvers & $\mathrm{J} 3$ & 3 & 1 & 1.0 & 2.5 & 3.0 & 1.5 & 33.75 \\
Narrow sidewalk (less than 0.5 m-wide) & $\mathrm{C} 6$ & 2 & 1 & 1.5 & 2.5 & 5.0 & 2.5 & 93.75 \\
Low planimetric radius & $\mathrm{G} 1$ & 3 & 0.9 & 1.0 & 2.5 & 2.5 & 2.5 & 42.19 \\
Not visible vertical road signs & $\mathrm{S} 5$ & 3 & 0.7 & 1.0 & 1.5 & 3.0 & 1.5 & 23.63 \\
Private access: lack of visibility & $\mathrm{A} 2$ & 3 & 0.9 & 1.0 & 2.5 & 2.5 & 1.5 & 25.31 \\
\hline
\end{tabular}

Figure $8 \mathrm{a}, \mathrm{b}$ represent two surveyed conditions which belong to Section n.4.

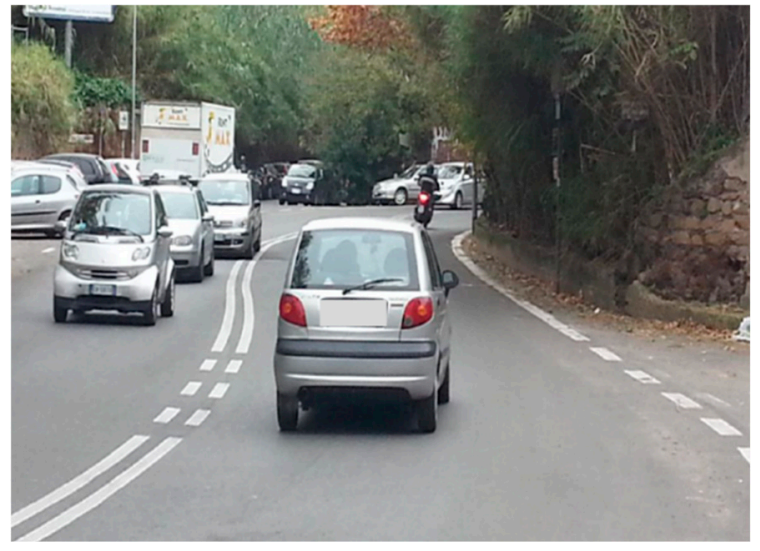

(a)

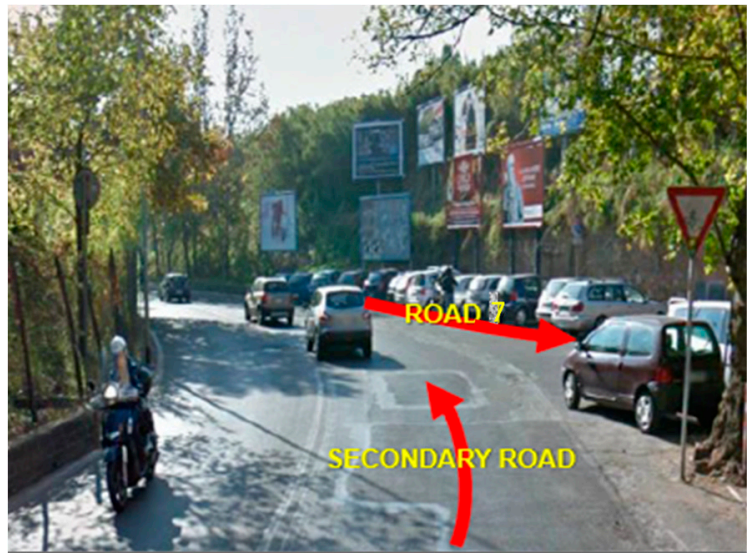

(b)

Figure 8. Section n.4 of ROAD7: example of surveyed conditions. (a) Low planimetric radius G1 $\left(B_{i}=3\right)$; (b) Hazardous maneuver J3 $\left(B_{i}=3\right)$.

The showed elements could cause rear-end collisions (Figure 8a), and head-on and lateral collisions (Figure $8 \mathrm{~b}$ ) along the examined section. Details about geo-referenced accidents are not available; therefore, it is not possible to correlate type of defects/elements and type of accidents: it is desirable that these data remain open for further investigation. 
The implementation of the proposed methodology allows the management body to identify and make decisions about the strategic priorities for interventions of safety improvement at section and branch levels: geometric, functional, and traffic data of the branches contribute to the assessment of the accident risk for vulnerable users. Indeed, the results are numerical and synthetic, and in decision-making processes, they could allow the management body to identify and to determine the strategic priorities about urban road safety.

Moreover, the proposed model could be modified to assess the index risk of urban intersections. Indeed, the proposed procedure could be modified (e.g., modification of the extension factor), and new relevant coefficients could be calibrated. Finally, the implementation of the approach both at section and at intersection levels could permit us to pursue a network-level approach.

\section{Conclusions}

The road transport sector is currently adopting growing measures to prevent accidents and reduce their consequences on people, especially on the most vulnerable users (e.g., pedestrians and cyclists).

This paper presents a quantitative risk analysis of deaths and serious injuries caused by urban road accidents. The study proposed a methodology based on the visual inspection to interpret the results from Road Safety Inspections on urban roads, to quantify the safety conditions, and to direct the competent bodies towards the most appropriate interventions.

The method depends on the assumed ranges of variables and risk classes, as well as on the values attributed to the variables used for calculating the hazard index of examined homogeneous road sections and branches. Therefore, both the Section Index Risk (SIR) and the Branch Index Risk (BIR) depend on geometric, functional, physical, and environmental defects or elements which are potential source of road accidents. These factors are then related to the involved vulnerable road users and to existing traffic flows to assess the current levels of risk. The categorization of these values into six levels of risk allows the identification of the most severe conditions and the prioritization of road safety works.

The results from surveying $50 \mathrm{~km}$ of roads in an Italian municipality demonstrated the good performance of the proposed tool in identifying, planning, and scheduling all the work required for improving urban road safety, because it is sensitive to improvements of infrastructure.

Moreover, the proposed methodology has both a diagnostic purpose, in order to evaluate whether there may be a correlation between the observed defects and the occurred accidents, and a preventive purpose, in order to correct defects or anomalies that could cause death or serious injuries of road users.

Author Contributions: Conceptualization, G.L.; Data curation, F.D.; Formal analysis, F.D.; Investigation, L.M.; Methodology, G.L.; Writing—original draft, L.M.; Writing—review \& editing, L.M. and G.L.

Funding: This research received no external funding.

Conflicts of Interest: The authors declare no conflict of interest.

\section{References}

1. ITF. Road Safety Annual Report 2017; OECD Publishing: Paris, France, 2017.

2. World Health Organization. Global Status Report on Road Safety 2013-Supporting a Decade of Action; World Health Organization: Geneva, Switzerland, 2013.

3. United Nations. Improving Global Road Safety. Resolution Adopted by the General Assembly on 2 March 2010; United Nations: New York, NY, USA, 2010.

4. European Commission. Roadmap to a Single European Transport Area-Towards a Competitive and Resource Efficient Transport System; White Paper, COM(2011) 144 Final; European Commission: Brussel, Belgium, 2011.

5. Canale, S.; Leonardi, S.; Pappalardo, G. The reliability of the urban road network: Accident forecast models. In Proceedings of the 3rd International Congress SIIV-People, Land, Environment and Transport Infrastructures, Bari, Italy, 22-24 September 2005. 
6. Cantisani, G.; Fascinelli, G.; Loprencipe, G. Urban road noise: The contribution of pavement discontinuities. In Proceedings of the 2012 International Conference on Sustainable Design and Construction, Fort Worth, TX, USA, 7-9 November 2012; pp. 327-334.

7. Di Mascio, P.; Fusco, G.; Grappasonni, G.; Moretti, L.; Ragnoli, A. Geometrical and functional criteria as a methodological approach to implement a new cycle path in an existing urban road network: A case study in Rome. Sustainability 2018, 10, 2951. [CrossRef]

8. Cantisani, G.; Loprencipe, G.; Primieri, F. The integrated design of urban road intersections: A case study. In Proceedings of the 2012 International Conference on Sustainable Design and Construction, Kansas City, MO, USA, 23-25 March 2012; pp. 722-728.

9. Mauro, R.; Cattani, M. Model to evaluate potential accident rate at roundabouts. J. Transp. Eng. 2004, 130, 602-609. [CrossRef]

10. Beck, B.; Cameron, P.A.; Fitzgerald, M.C.; Judson, R.T.; Teague, W.; Lyons, R.A.; Gabbe, B.J. Road safety: Serious injuries remain a major unsolved problem. Med. J. Aust. 2017, 207, 244-249. [CrossRef] [PubMed]

11. Corazza, M.V.; Musso, A.; Finikopoulos, K.; Sgarra, V. An analysis on health care costs due to accidents involving powered two wheelers to increase road safety. Transp. Res. Procedia 2016, 14, 323-332. [CrossRef]

12. Piantini, S.; Baldanzini, N.; Pierini, M.; Mangini, M.; Franci, A.; Peris, A. An Overview on Pedestrians and Cyclists Serious Injuries in Urban Accidents. In Proceedings of the International Research Council on Biomechanics of Injury (IRCOBI), Zurich, Switzerland, 9-11 September 2015.

13. Lamm, R.; Mailaender, T.; Psarianos, B. Highway Design \& Traffic Sagety Engineering Handbook; Mc Graw Hill: New York, USA, 1999.

14. Abojaradeh, M.; Jrew, B.; Al-Talafeeh, A. The Effect of Driver Behavior Mistakes on Traffic Safety. Civ. Environ. Res. 2014, 6, 39-54.

15. Madsen, T.K.O.; Lahrmann, H. Comparison of five bicycle facility designs in signalized intersections using traffic conflict studies. Transp. Res. Part F 2016, 46, 438-450. [CrossRef]

16. Nitsche, P.; Saleh, P.; Helfert, M. Forgiving Roadside Design Guide: Improving Roadside Design to Forgiven Human Errors Deliverable n. 3-Annex 1: State of the Art Report on Existing Treatments for the Design of Forgiving Roadside. 2011. Available online: http://www.cedr.eu/download/other_public_files/research_ programme/eranet_road/call_2009_safety/irdes/04_IRDES_D3_Forgiving_Roadside_Guidelines_V2.0_31.1. 2012.pdf (accessed on 16 November 2018).

17. Corazza, M.V.; Di Mascio, P.; Moretti, L. Managing sidewalk pavement maintenance: A case study to increase pedestrian safety. J. Traffic Transp. Eng. 2016, 3, 203-214. [CrossRef]

18. Corazza, M.V.; Di Mascio, P.; Moretti, L. Management of sidewalk maintenance to improve walking comfort for senior citizens. WIT Trans. Built Environ. 2018, 176, 195-206.

19. European Commission. Directive 2008/96/EC of the European Parliament and of the Council of 19 November 2008 on Road Infrastructure Safety Management; European Commission: Brussel, Belgium, 2008.

20. Parlamento Italiano. Decreto Legislativo n. 35/2011. Attuazione della Direttiva 2008/96/CE sulla Gestione della Sicurezza delle Infrastrutture Stradali (Implementation of the European Directive 2008/96/CE Concerning the Road Safety Management); Parlamento Italiano: Rome, Italy, 2011.

21. Ministero delle Infrastrutture e dei Trasporti. Linee Guida per la Gestione della Sicurezza delle Infrastrutture Stradali; Ministero delle Infrastrutture e dei Trasporti: Rome, Italy, 2012.

22. Jamroz, K.; Budzyński, M.; Kustra, W.; Michalski, L.; Gaca, S. Tools for road infrastructure safety management-Polish experiences. Transp. Res. Procedia 2014, 3, 730-739. [CrossRef]

23. Kustra, W.; Michalski, L. Tools for road infrastructure safety management in Poland. In Proceedings of the MATEC Web of Conferences 2017, Sun Moon Lake, Taiwan, 29 September-2 October 2017.

24. Alfonsi, R.; Persia, L.; Antonino, T.; Usami, D.S. Advances in Road Safety Management Analysis. Transp. Res. Procedia 2016, 14, 2064-2073. [CrossRef]

25. Persia, L.; Usami, D.S.; De Simone, F.; Beaumelle, V.F.D.L.; Yannis, G.; Laiou, A.; Han, S.; Machata, K.; Pennisi, L.; Marchesini, P.; et al. Management of Road Infrastructure Safety. Transp. Res. Procedia 2016, 14, 3426-3445. [CrossRef]

26. Lynam, D. Development of Risk Models for the Road Assessment Programme; International Road Assessment Programme: London, UK, 2012.

27. American Association of State Highway and Transportation Officials (AASHTO). Highway Safety Manual, 1st ed.; AASHTO: Washington, DC, USA, 2010. 
28. American Association of State Highway and Transportation Officials (AASHTO). An Introduction to the Highway Safety Manual; AASHTO: Washington, DC, USA, 2010.

29. Appleton, I. Road Infrastructure Safety Assessment. In Proceedings of the 4th IRTAD Conference, Soul, Korea, 16-17 September 2009.

30. Koorey, G.; Carpenter, M.; Appleton, I. Technical Note-Safety Audits of Existing Roads Database. In Proceedings of the IPENZ Transportation Group Technical Conference, Christchurch, New Zealand, 17 September 2003.

31. Quezon, E.T.; Wedajo, T.; Mohammed, M. Analysis of Road Traffic Accident Related of Geometric Design Parameters in Alamata-Mehoni-Hewane Section. Int. J. Sci. Eng. Res. 2017, 8, 874-881.

32. Loprencipe, G.; Moretti, L.; Cantisani, G.; Minati, P. Prioritization methodology for roadside and guardrail improvement: Quantitative calculation of safety level and optimization of resources allocation. J. Traffic Transp. Eng. 2018, 5, 348-360. [CrossRef]

33. Loprencipe, G.; Cantisani, G.; Di Mascio, P. Global assessment method of road distresses. Life-Cycle of Structural System: Design, Assessment, Maintenance and Management. In Proceedings of the 4th International Symposium on Life-Cycle Civil Engineering, Tokyo, Japan, 16 November 2014; CRC Press: Leiden, The Netherlands, 2015.

34. EuroRAP 2009. Star Rating Road for Safety: The EuroRAP Methodology; European Road Assessment Programme: Brussels, Belgium, 2009.

35. Transportation Research Board. Incorporating Reliability Performance Measures into the Transportation Planning and Programming Processes: Technical Reference; SHRP 2 Report S2-L05-RR-3; The National Academies Press: Washington, DC, USA, 2014.

36. Cafiso, S.; D'Agostino, C.; Persaud, B. Investigating the influence of segmentation in estimating safety performance functions for roadway sections. J. Traffic Transp. Eng. 2018, 5, 129-136. [CrossRef]

37. Ministero delle Infrastrutture e dei Trasporti. Norme Funzionali e Geometriche per la Costruzione delle Strade; Italian Ministry of Transportation Decreto Ministeriale: Rome, Italy, 2001.

38. Ministero delle Infrastrutture e dei Trasporti. Norme Funzionali e Geometriche per la Costruzione delle Intersezioni Stradali; Italian Ministry of Transportation Decreto Ministeriale: Rome, Italy, 2006.

39. UNI. UNI 10439:2001: Illuminotecnica-Requisiti Illuminotecnici delle Strade con Traffico Motorizzato; Ente Italiano di normazione: Rome, Italy, 2001.

40. Transportation Research Board. Highway Capacity Manual: A Guide for Multimodal Mobility Analysis, 6th ed.; The National Academies Press: Washington, DC, USA, 2016.

41. Croft, A.C.; Freeman, M.D. Correlating crash severity with injury risk, injury severity, and long-term symptoms in low velocity motor vehicle collisions. Med. Sci. Monit. 2005, 11, RA316-RA321. [PubMed]

42. Beck, B.; Stevenson, M.; Newstead, S.; Cameron, P.; Judson, R.; Edwards, E.R.; Bucknill, A.; Johnson, M.; Gabbe, B. Bicycling crash characteristics: An in-depth crash investigation study. Accid. Anal. Prev. 2016, 96, 219-227. [CrossRef] [PubMed]

43. Kröyer, H.R.G. Is $30 \mathrm{~km} / \mathrm{h}$ a 'safe' speed? Injury severity of pedestrians struck by a vehicle and the relation to travel speed and age. IATSS Res. 2015, 39, 42-50. [CrossRef]

44. Cameron, M.H.; Elvik, R. Nilsson's Power Model connecting speed and road trauma: Applicability by road type and alternative models for urban roads. Accid. Anal. Prev. 2010, 42, 1908-1915. [CrossRef] [PubMed]

45. Biswas, S.; Singh, B.; Saha, A. Assessment of level-of-service on urban arterials: A case study in Kolkata metropolis. Int. J. Traffic Transp. Eng. 2016, 6, 303-312. [CrossRef]

46. Wramborg, P. A new Approach to a Safe and Sustainable Traffic Planning and Street Design for Urban Areas. In Proceedings of the Road Safety in Four Continents Conference, Warsaw, Poland, 5-7 October 2005.

47. Bonin, G.; Folino, N.; Loprencipe, G.; Oliverio Rossi, G.; Polizzotti, S.; Teltayev, B. Development of a road asset management system in Kazakhstan. In Proceedings of the 1st TIS 2017 International Congress on Transport Infrastructure and Systems, Rome, Italy, 10-12 April 2017.

48. Di Mascio, P.; Loprencipe, G. Risk analysis in the surrounding areas of one-runway airports: A methodology to preliminary calculus of PSZs dimensions. J. Eng. Appl. Sci. 2016, 11, 13641-13649.

49. Moretti, L.; Cantisani, G.; Caro, S. Airport veer-off risk assessment: An Italian case study. ARPN J. Eng. Appl. Sci. 2017, 12, 900-912. 
50. Moretti, L.; Cantisani, G.; Di Mascio, P.; Nichele, S.; Caro, S. A runway veer-off risk assessment based on frequency model: Part I. Probability analysis. In Proceedings of the 1st AIIT International Congress on Transport Infrastructure and Systems, Rome, Italy, 10-12 April 2017.

51. Moretti, L.; Cantisani, G.; Di Mascio, P.; Nichele, S.; Caro, S. A runway veer-off risk assessment based on frequency model: Part II. Risk analysis. In Proceedings of the 1st AIIT International Congress on Transport Infrastructure and Systems, Rome, Italy, 10-12 April 2017.

52. Moretti, L.; Di Mascio, P.; Nichele, S.; Cokorilo, O. Runway veer-off accidents: Quantitative risk assessment and risk reduction measures. Saf. Sci. 2018, 104, 157-163. [CrossRef]

53. Di Mascio, P.; Perta, G.; Loprencipe, G. The public safety zones around small and medium airports. Aerospace 2018, 5, 46. [CrossRef]

54. Mooney, C.Z. Monte Carlo Simulation; No. 116; Sage: London, UK, 1997.

55. Scozzafava, R. Primi Passi in Probabilità e Statistica (Basics of Probability and Statistics); Zanichelli Editore: Bologna, Italy, 1995.

56. ISTAT. Incidenti Stradali in Italia; Istituto Nazionale di Statistica: Rome, Italy, 2016.

(C) 2018 by the authors. Licensee MDPI, Basel, Switzerland. This article is an open access article distributed under the terms and conditions of the Creative Commons Attribution (CC BY) license (http://creativecommons.org/licenses/by/4.0/). 